\title{
Interactive Placemaking - Prototype of an Intelligent Urban Building Infrastructure for Critical Borderlands / Kinmen
}

\author{
Li-Yen Hsu ${ }^{1}$ \\ ${ }^{1}$ Head Architect, HSU Studio, Taiwan \\ Correspondence: Li-Yen Hsu, HSU Studio, Hsinchu (30071), Taiwan. Tel: 886-921-179-856. E-mail: \\ liyenhsu@ms19.hinet.net
}

Received: June 1, 2018

Accepted: June 12, 2018

Online Published: June 30, 2018

doi:10.5539/mas.v12n7p128

URL: https://doi.org/10.5539/mas.v12n7p128

The research is partially financed by Kinmen county government, Fujian, Republic of China.

\begin{abstract}
Dependable capabilities to counter wicked tasks are proactively needed for borderland placemaking. Initiated recently, in Xiamen, a hub airport is being constructed at Xiangan district's Dadeng islet, which was taken after the inner war from the outlying borderland of Taiwan - Kinmen. To promote current interactive urbanizing, holistic pervasiveness, and/or resource chaining, a sensor-information infrastructure with availability, reliability, and maintainability features through artificial intelligence -i.e., the plural surveillances, similar in sensing through creatures' eyes, ears, and nostrils- is prototyped. By plural detection along traffic paths, such dedicated short-range communication networks, evidenced with terrorist uncertainty, can help promote trust, inclusive accessibility, mobile services, and interactive measures, with fault tolerance, Hamiltonian (a mathematical order), connectivity, scalability, electromagnetic interference countering, and reliable accuracy. More flexibility can be justified for the emerging pervasive logistic and security management demand by further applying other network types. The cubeconnected cycle is prototyped for the probe application along waterways and in rural areas. The prototyped spiderweb network can be resiliently integrated with shorelines and interior paths and configured together into a featured urban building context, radial-ring, whose sustainability is culturally resonated in world heritage, neighboring Tulous; help promote peace developing and evoke economic interactions, globally.
\end{abstract}

Keywords: artificial intelligence (AI), borderland placemaking, dedicated short-range communication (DSRC) network, dependability, prototyping

\section{Introduction-Managing Uncertainty}

Global changes, including the rise of the sea level and frequent terrible attacks, are apparently threatening the living environment (Fisher 2013; Hsu 2017). Although traditionally, negative concerns may be aroused when people consider the operated surveillance, the aggressive surveillance (typically with cameras), in the last two decades, has become emphatically required, e.g. in casinos and theme parks (Gottdiener \& Budd 2005, p.113).

Contemporary sensor-information networking can hardly be seen, besides means of passive crime prevention through environmental design (Atlas 2013), "prototyping" (Fisher 2014, as the methodology, in Section 3), more holistic (everywhere or concerning availability) (Hsu 2017, Saha, Mkheryjee \& Bandyopadhyay 2012; Slessor 2018], (Fig.1) and reliable (all-time) networking, is becoming critical to facilitate profiling events in real time (Syrett \& Devine2012), to protect and serve travelers and residents, and to prevent incidents, counter disasters, environmental challenges (Atlas 2013; Bloom 2013; Coaffee 2003, 2009; Graham 2004) and/or other wicked problems (APSC 2007; Fischbacher-Smith 2016; Fisher 2014), i.e. problems that are difficult to anticipate) (Fig.2).

The bus fire in Fig. 1 can be named as "2016 Taoyuan bus fire" and can be referred to in the public media, including Wikipedia. This event and the new London embassy (Slessor 2018) are evidenced that the planning of holistic environmental control is needed to grasp the dynamical consequence of incremental changes or to counter intentional terrorist attacks in the real-time. Pervasiveness is the quality of spreading widely or being present throughout an area or a group of people. Pervasive computing is an emerging development (Saha, Mkheryjee, \& Bandyopadhyay 2012; Lee et. al 2005). In terms of prototyping systematic availability, the methodology of this research can also be described as design or task based, and holistic pervasiveness is the quality aimed (Levy 2007; 
Petrich 1993).

Disasters due to human intentional behaviors (or not purely caused by natural disasters) can hardly be foreseen based on previous recordings; i.e. "forecasts are always wrong" need be emphasized (De Neufville \& Odoni 2003; De Neufville \& Scholtes 2011) - especially if real-time pervasiveness is demanded. Well enhancing dependable capabilities, i.e. ARM, or "availability, reliability, and maintainability" (Daley 2011; Knezevic 1997), to strategically create resource utilization (Grant 2014; Hill, Schilling \& Jones 2017) and trust development is the foundation of successful placemaking (Robbins \& Coulter 2012; Schneekloth \& Shibley 1995; Tilly 2011).

In conflict sensitive areas, e.g. around the Taiwan's outlying former battlefield, Kinmen, an interactive and peaceful society had been evidenced essential for promoting regional inverstments and stakeholder benefits (Ye 2014). More effective, efficient capabilities on prevention or mitigation of wicked acts should be considered, through prototyping and with integrative and public welfare oriented minds, before disasters really happen (Fisher 2014). Well applying emerging information technologies, public opinions can more easily be interactively deliberated (Perulli 2017), and well urbanizing (Sassen 2015) can be hopefully promoted, even in borderland areas.

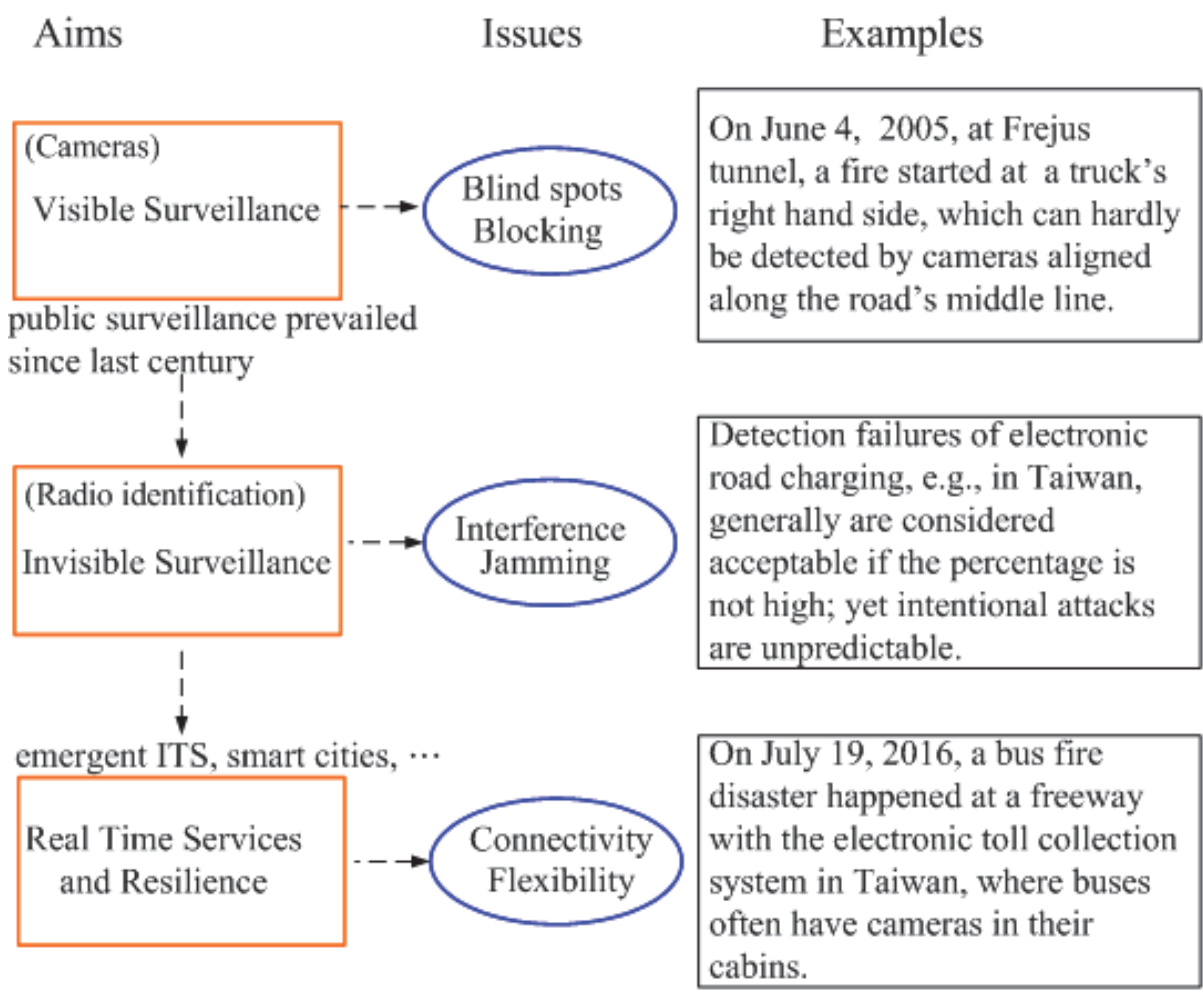

Figure 1. Evolvement of systematic, holistic plural surveillance networking

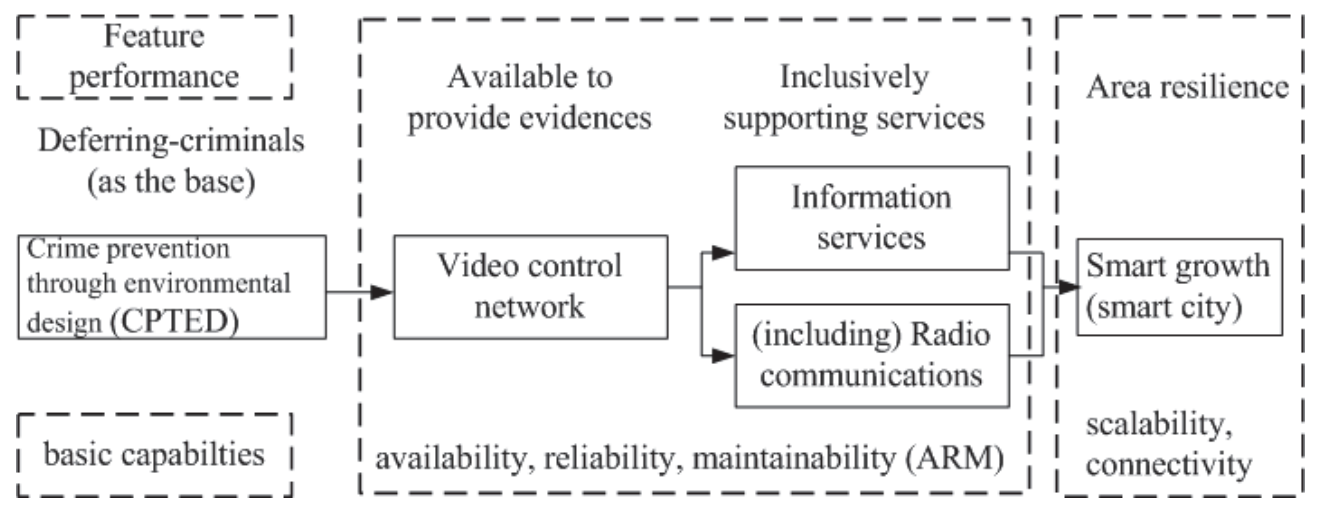

Figure 2. Evolvement of surveillance to support smart urban growth 
To build stakeholders' trust, offering information with integrity, openness, competence, and consistency (Robbins \& Coulter 2012) is urgent, especially when it is related to health and security, which is also the most critical concern in border inspection. Nevertheless, the facilities concerning attacks through advanced technologies, e.g. through the unmanned aerial vehicle (drone), which can hardly be detected by the roadside surveillance due to it being small and probably very far, are getting more concerns (Hoppe \& Awsede 2013, p.215). Such drones are being considered to be legally utilized, e.g. for logistic application; however, they should be detectable, manageable along each lane of the path. In areas off roadside surveillance, more networking studies are considered needed (Hsu 2013, e.g. the network honeycomb torus is introduced for cellular communication applications).

Consequently, the demand of artificial intelligence (AI) or biologic plural surveillance such as two (dual) eyes, two nostrils, or two ears and/or the combination of different senses' facilitating surveillance is suggested and can be evidenced from traffic disasters (Hsu 2017, 2008) (Fig.1). Nevertheless, if a single device can provide differential data, e.g., by sending a differential radio frequency for spatial analization, as with differential radar (Zhou, Chen \& Guo 2015), then it can be deemed as an intrinsic plural (dual) node.

The infrastructural path's governance and information service system, such as the electronic road pricing (ERP), has been successfully applied together with radio frequency identification (RFID) and cameras to reduce city area traffic in Singapore since the twentieth century (Gómez-Ibáñez \& Small 1994) The same method has been used to charge fees on toll roads (e.g. freeways in Taiwan), and is called an electronic toll collection (ETC) system. ERP or ETC can be classified as types of dedicated short-range communication (DSRC), which is an element in intelligent transport systems (ITS) (Fig.1).

Radio communication integrity fundamentally depends on fault-tolerance and the capability to overcome environmental challenges such as clogged water, dynamic occlusion, radio interference and jamming (Anderson, Kalra, Stanley, Sorensen, Samaras \& Oluwatola 2016; Hsu 2017). The application of plural surveillance nodes incorporated with the multiple-input multiple-output (MIMO) (Li 2013) technology is inherent to these systems for enhancing radio communication integrity and supports privacy and security through systematic, collaborative inspections without loss and repetition, i.e. the mathematical Hamiltonian properties (see Section 3, 4).

If a communication path includes "interior paths", its telecommunication transmission time periods can have limited increase due to its transmission speed as quick as the light's. Such time related attributes can help practically network a defensive radial-ring configuration, which can holistically promote sensor-information network pervasiveness in defense demanded Kinmen, similarly to neighboring Tulous (earth buildings) the world heritage, whose defensive, operational skeletons are inherent "radial-rings" (Fig.3, Section 2), or the mathematical spider-web networks.

In other words, the radial-ring network pattern that has topological wholeness and adaptation features can be the means of prototyping (Salingaros 1999). That pattern is able to coordinate with the city-building skeleton (Fisher 2014) and historical formation image (see Section 2). Its holistic legibility, as Lynch (1960) (i.e., wholeness perception or Gestalt perception) (Malnar \& Vodvarka 2004: Dovey 2016; Arthur \& Passini 1992), can help tourism cognition and general wayfinding so that such legibility is directly related to the success of a urban plan, able to be promoted for the future in the following integral strategic perspective, "utilizing resources and enhancing trustworthy, dependable capabilities" (Hill, Schilling \& Hones 2017; Grant 2014; Salingaros 2010).

\section{Literature Review: Holism, Resilience, and Sustainability}

\subsection{Fair Linking Creates Pros $\rightarrow$ "Resource"}

Along a (shore / street) line, vendors typically select a central location to optimize vending opportunities due to short-distance advantages, from the perspective of ease of accessibility to customers and creating a fair market order (Fig.3). This relates to a concept in city planning, namely, a radial-ring configuration that can help extend protection and services between the center and outer areas (Keeble 1969; Batty \& Longley 1994; Batty 2008). Moreover, the grid pattern can be adapted to be a radial-ring if the center can be rationally assumed (Fig.4).

Hence, practicing fractal yet largely radial-rings (Batty 2008), which is consistent with the adaptable grid layouts, is inherently related to the efficiency of urban economies and defense. Hence, using radial-rings is inherently related to the efficiency of city-building and/or defense. Moreover, it should be noted that "dynamic" operations, such as those in the Roman Testudo formation (Fig.3(a)), may hardly be visible in its static radial-ring (or grid) form; nevertheless, a city or an area can have more than one radial-ring form, i.e. related to the aforementioned fractal, which can be further applied through mathematical connectivity.

Regarding the connectivity level promotion on modern urban spaces, especially in politically sensitive cities or mega-cities (Gottdiener \& Budd 2005, p. 136, p.186; Salingaros 2005, 2010), sufficient public telecommunication 
systems with security facilities are required to counter crimes and even terrorist activities. Such security and information service networks can be known as the supervisory control and data acquisition system, which has been applied in spatial management in tunnels (Bickel, Kusel \& King 1996); however, this terminology is seldom used in traffic management. Basically, the DSRC is instead often used in providing path services and protection support for both customers and the administration. Such security information may be transferred through "radio communications" and is not necessarily limited in critical infrastructures. For such "invisibility" developments, dependable capabilities- availability, reliability and maintainability are getting more importance.

The territories of Cross-Taiwan-Strait entities meet at Kinmen-Xiamen, or the south metropolitan area (i.e., Xiamen, Zhangzhou, Quanzhou, and sometimes including Kinmen - especially being considered as a trend of "same-city") of the Fujian Province, the potential aerotropolis - based on the characteristics being able to be achieved and the term - airport city "metropolitan" area - in (Ashford, Mumayiz \& Wright 2011, pp.660-661) of which is centered in Xiamen's an islet of the "current" Xiangan District, where was known as Kinmen's Dadeng islet prior to 1949 (CNA 2014; WOX 2014).

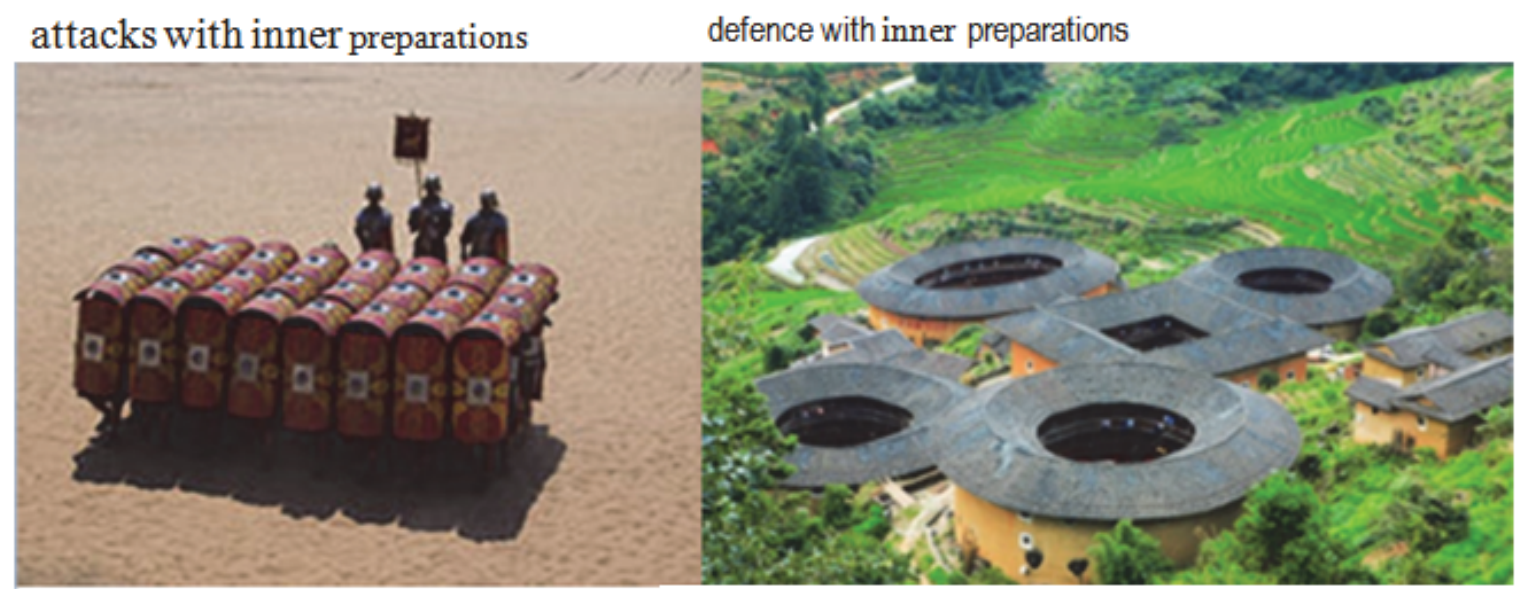

https://en.wikipedia.org/wiki/Testudo_formation

(a)

https://2h.wikipedia.org/wiki/\$6E7\%A6\%68F\%E5\%BBB6BA\%EE569C\%69F\%666\%A5\%BC (b)

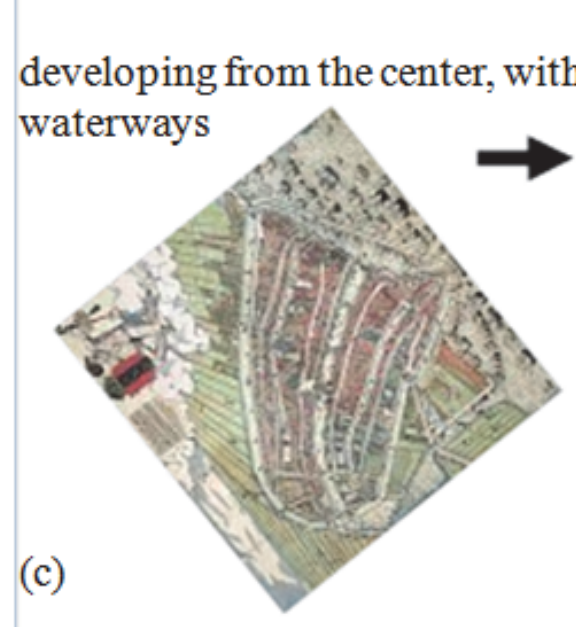

https://en.wikipedia.org/wiki/Amsterdam

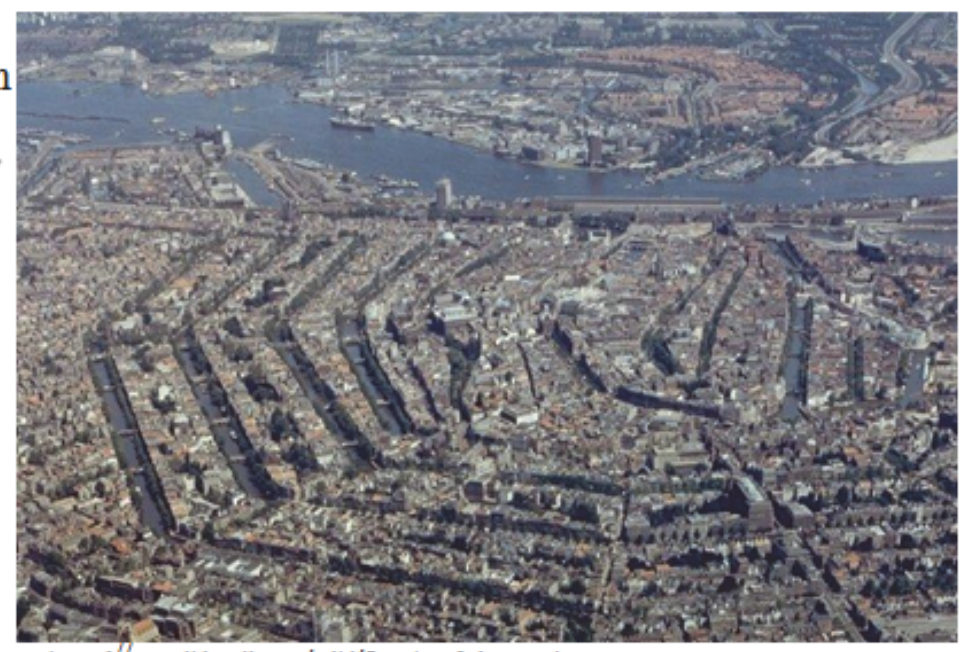

https://en.wikipedia.org/wiki/Canals_of_Amsterdam

Figure 3. Radial-ring central, short-distance advantages; for: (a) active attacks - Testudo formation, (b) passive defense - Tulous, (c) compact land-use, e.g., w. waterways - Canals of Amsterdam [original source: Bureau Monumenten \& Archeologie of Amsterdam]

After more than 60 years of war, in 2010 Taiwan (the Republic of China) and mainland China (the People's Republic of China) (Fig.5) signed an economic cooperation framework agreement (terminology refer to public media including Wikipedia for further terminology detail). Kinmen county (Kinmen) is administered by the Taiwan authority, yet it is on the west side of the Taiwan Strait and very close to mainland China (Fig.5-which also shows that the radial-ring worked as a defensive formation in 1949). 

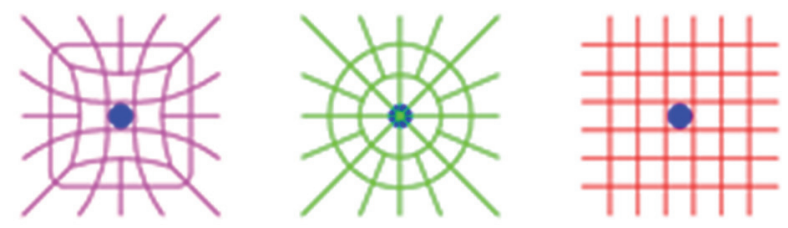

Figure 4. Grid can be coded as the radial-ring or the spider-web pattern (Keeble 1969, p.112)

Hence, Kinmen County can potentially be linked with various regional benefits due to its emerging competent global accessibility (Stevens, Baker \& Freestone 2010, Ye 2014). However, regarding the potential disadvantages of this new airport project, different concerns have emerged, including cross-border terrorist attacks and increased vulnerability to disease (Brenner \& Keil 2006; Goodwin 2011). It is noted that both Kinmen and Xiamen were a part of Quanzhou, which had been one of the largest port cities in the world and the starting point of the Maritime Silk Road, also one origin of the $21^{\text {st }}$ century Maritime Silk Route economic belt (a large-scale regional corporation proposal; refer to public media including Wikipedia for terminology). Consequently, whether Kinmen's placemaking is successful or disastrous can potentially globally affect the interests of many people.

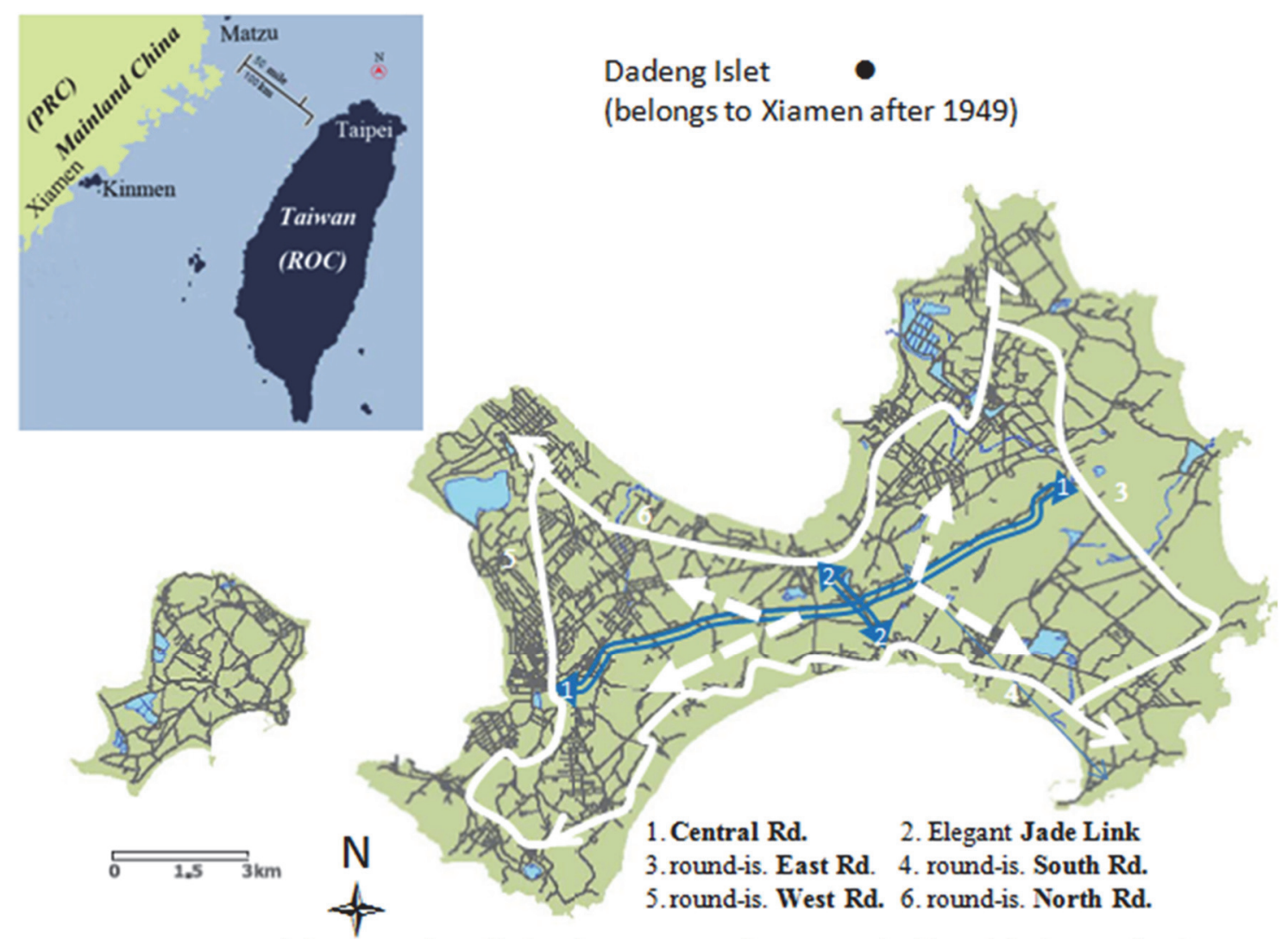

Kinmen government's base map: http://urban.kinmen.gov.tw/kmgis_new/publicweb/index.aspx?web=1

Figure 5. Kinmen's strategic location and its one radial-ring defensive pattern [copyright inquiry available through Kinmen county government, e.g., http://leaderbox.kinment.gov.tw]

\subsection{Adaptation Creates Amenities $\rightarrow$ “Capability”}

Similar to a military formation, the security of a built-up area must be reliably operated and carefully maintained, including all interlinking passages, such as waterways. Interference or occlusion should be prevented. Formationlike constructions, the topological features of which effectively facilitate satisfying the human needs of economy, security, and community care can be found in examples of world cultural heritage, such as the canals of Amsterdam, the Netherlands and the Tulou in the Fujian Provence, China (Fig.3(b),(c)).

Hence, the node and link fault tolerance-based prototype, especially the radial-ring patterned, with an optimal 
degree (degree is the number of links connected to a node) of three for designing pervasive, reliable security information networks chiefly applied along probably busy traffic conditioned paths, are considered here and then mathematically assured. The referred radial-ring pattern can offer both cultural and mathematical values.

Mathematically, it is resilient, and that resiliency can enhance livable, peaceful urbanism (Salingaros 2005). Culturally, Kinmen's neighboring Tulous are known for having resilience via defensive radial-ring operations (yet having differences, see Section 5.1), and imitating such cultural constructs can benefit regional friendliness, peaceful collaborations, and then create tourism benefits. However, from the perspective of Kinmen's developmental planning, the reliability and integrity of information networks must be considered in managing infrastructure security to create sustainable opportunities and resources (Levy 2007, pp.356-357; Salingaros 2005; Weber 2002), mutual/cross-strait benefits (Caudle 2009; Terlouw 2012), trust (Robbins \& Coulter 2012; Schneekloth \& Shibley 1995; Tilly 2011), and peace.

The proposed radial-ring is not a monotonous geometry, and should not be, (i.e., should consider customers' unique interests and different environmental conditions) because a difference between topology and geometry is that a straight line is identical to a messy, curved, or shoestring-like line (Arthur \& Passini, p.105) in topology. Moreover, considering topology can help justify spatial design with better background adaptations and/or humanistic flavors but still support rational wayfinding attributes, according to ordinary human visions. Furthermore, Kinmen's radial-ring images should be highlighted to strengthen intrinsic peaceful and cultural meanings.

Nevertheless, contemporary inclusive (barrier-free) radio communication technologies facilitated on paths is getting more importance in assisting wayfinding, accessing mobile information or real-time knowledge, promoting quality of life (Steinfeld \& Maisel 2012; Tumlin 2012; Yigitcanlar 2014), and countering wicked or difficultly anticipated problems. It is recommended that it be studied with integrative and public welfare oriented "prototyping" (Fisher 2014), which is the essential background of this article's methodology. Besides, because this prototyping study is related to spatial adaption and linking, i.e. one link pattern can represent either a messily curved or a highlighted shoestring-like line, it is related to topology, graph theory, or mathematics, which is a science of patterns, especially on those denoting regularity (Salingaros 1999).

In summary, this "prototyping" research, e.g., in terms of systematic availability, is task or design based. Design is a specific "problem-solving innovation" emphasized discipline although its methodology is probably hardly translated to other disciplines (Malnar \& Vodvarka 2004, p.44); nevertheless cultural (Malnar \& Vodvarka 2004, p.6), ecological, and other essential features through prototyping are suggested to be collaboratively analyzed and assessed (Fisher 2014; Malnar \& Vodvarka 2004).

\section{Method: AI Oriented Prototyping}

Communication networks are typically represented by graphs in which nodes represent processors and edges represent links between processors. Notably, mathematically scalable performance is beneficial in building up a network prototype. Scalability is also important for establishing a communication and information sensor-node platform for flexible support, offering the possibility for dealing with different environmental conditions. The mathematical Hamiltonian order facilitates guaranteeing that maintenance is performed appropriately (without loss, and efficiently). This paper proposes an approach for reliably establishing communication and information networks for serving areas that require considerable amounts of sensor nodes.

Let $G=(V, E)$ be a graph if $V$ is a finite set and $E$ is a subset of $\{(a, b) \mid(a, b)$ is an unordered pair of $V\}$. A path is delimited by $\left(x_{0}, x_{1}, x_{2}, \ldots, x_{n-1}\right)$ and called a Hamiltonian path if its nodes are distinct and span $V$. A cycle is a path of at least three nodes where the first node is the same as the final node. A cycle is called a Hamiltonian cycle or "Hamiltonian" if its nodes are distinct except for the first and last nodes, and if they span $V$ (Hsu \& Lin 2008).

A bipartite graph $G=(V, E)$ is a graph where $V=A \cup B$ and $E$ is a subset of $\{(a, b) \mid a \in A$ and $b \in B\}$; if $G-F$ remains Hamiltonian for any $F=\{a, b\}$ with $a \in A$ and $b \in B$, then $G$ is $1 p$-Hamiltonian. A graph $G$ is 1 -edge Hamiltonian if $G$-e is Hamiltonian for any $e \in E$; moreover, if there is a Hamiltonian path between any pair of nodes $\{c, d\}$ with $c \in A$ and $d \in B$, then the bipartite graph $G$ is Hamiltonian laceable (Fig.6, 7). Notably, laceability is used with respect to connectivity to ensure that extended areas are integrated (or vice versa) and an area can be managed collaboratively or hierarchically yet effectively.

The bipartite spider-web network $\operatorname{SW}(m, n)$ is a graph (Fig.6) with the node set $\{(i, j) \mid 0 \leq i<m, 0 \leq j<n\}$, where $\mathrm{m}$ and $\mathrm{n}$ are even integers with $\mathrm{m}, \mathrm{n} \geq 4$, such that $(i, j)$ and $(k, l)$ are adjacent if they satisfy one of the following conditions: (1) $i=k$ and $j=l \pm l$; (2) $j=l$ and $k=i+1(\boldsymbol{m o d} m)$ if $i+j$ is odd or $j=n-1$; or (3) $j=l, k=i-1(\boldsymbol{m o d}$ $m)$ if $i+j$ is even or $j=0$. SW $(m, n)$ is proved to be 1-edge Hamiltonian and $1_{\mathrm{p}}$-Hamiltonian (Kao \& Hsu 2005a). Thus, the fault tolerance is systematically based. Moreover, $S W(m, n)$ are Hamiltonian laceable (Kao \& Hsu 2005b) 
(Fig.6(a)).
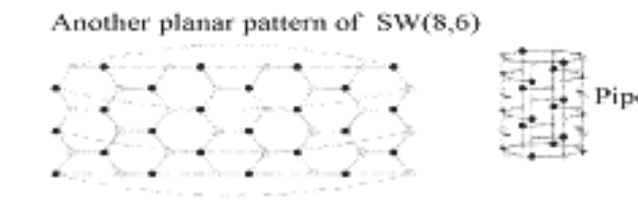

The adjacent area-SCADA network can be merged into the radial-ring skeleton.

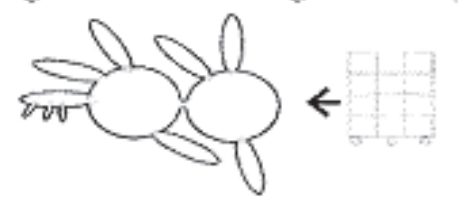

An SW network as the main skeleton with SW subnetworks as its edge
$\mathrm{SW}(\mathrm{m}, \mathrm{n})$ is hamiltonian laceable. Two combined

hamiltonian laceable graphs can be hamiltonian

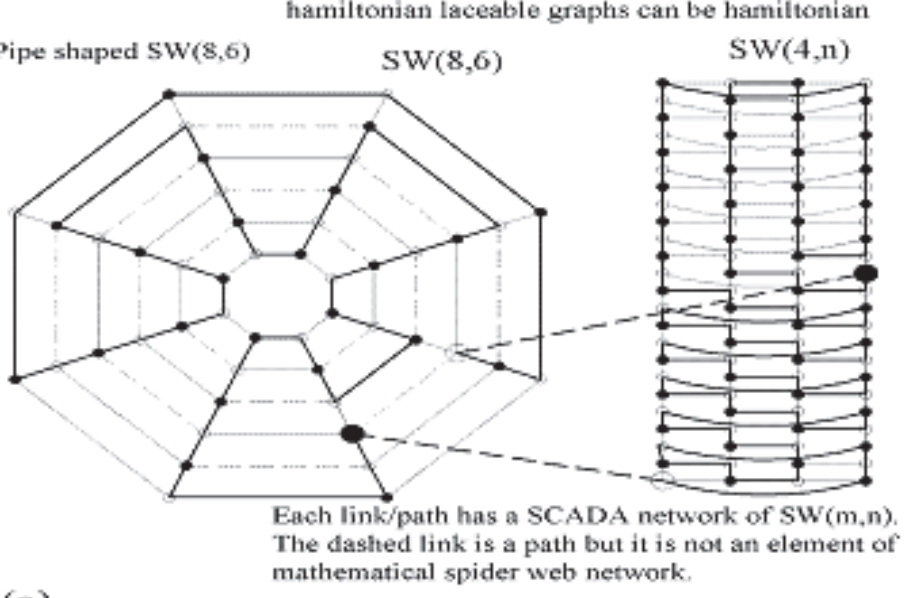

(a)

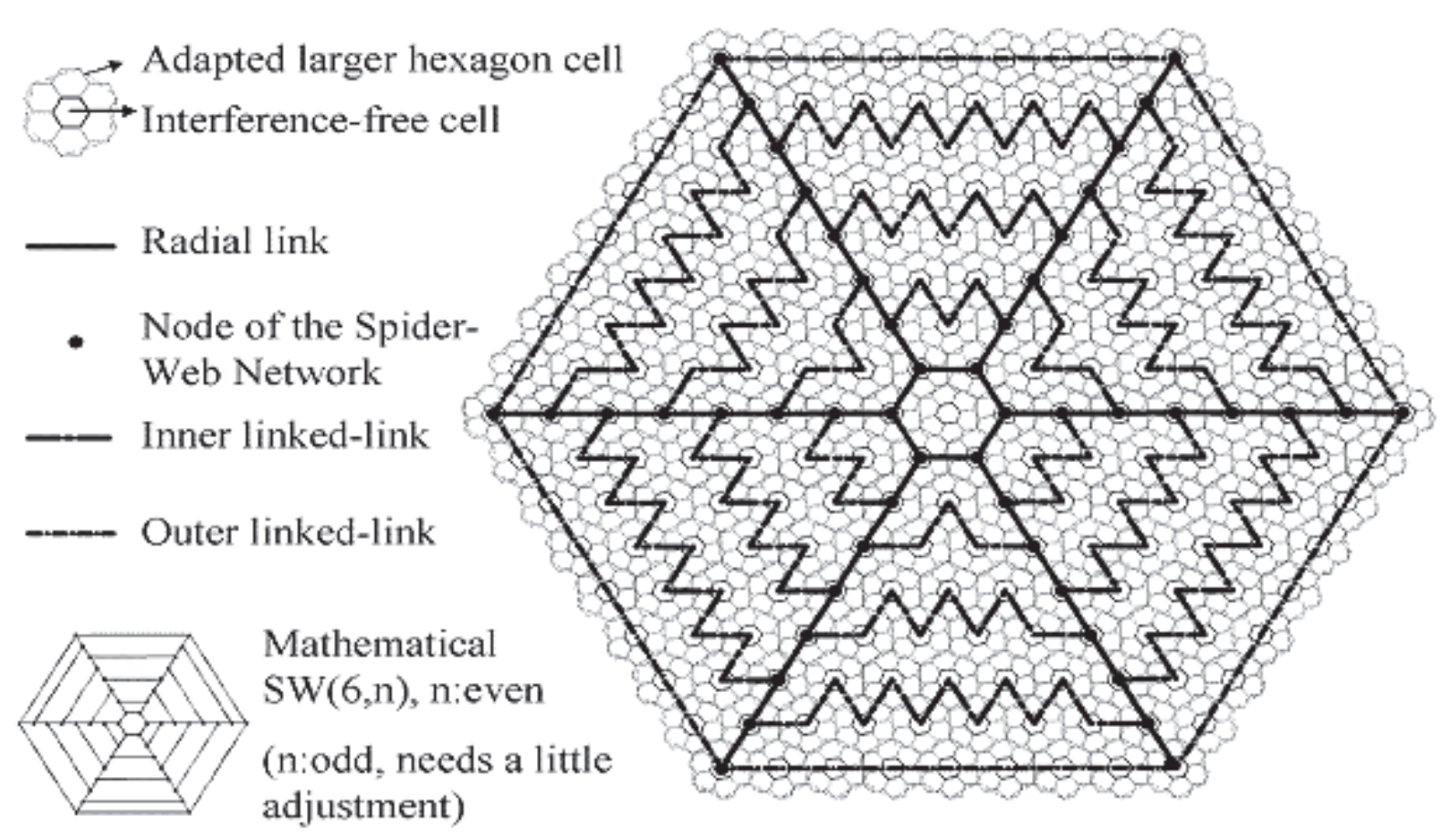

(b)

Figure 6. Spider-web network: (a) individual spider-web networks can be integrated to form a laceable area network; (b) an interference prevention oriented network composed of a spider-web network, $\operatorname{SW}(6, \mathrm{n})$, employing frequency hopping to differentiate the frequency used in adjacent cells, economically using the frequency spectrum for multiple access (Hsu 2013).

The number of links connecting a node is called the degree; a network that regularly possesses fewer degrees is generally economical (Stojmenovic 1997). This is the reason for considering the network prototype with a regular degree of three, designed as the optimal base to facilitate node fault tolerance and incorporation, and to counter occlusion. Two Hamiltonian paths $\left.P_{1}=u_{1}, u_{2}, \ldots, u_{n}(G)\right)$ and $P_{2}=\left(v_{1}, v_{2}, \ldots, v_{n}(G)\right)$ of $G$ from $u$ to $v$ are independent if $u=u_{l}=v_{l}, v=u_{n}(G)=v_{n}(G)$, and $u_{i} \neq v_{i}$, for every $1<i<n(G)$. A set of Hamiltonian paths, $\left\{P_{l}, P_{2}, \ldots, P_{k}\right\}$, of $G$ from $u$ to $v$ is mutually independent if any two Hamiltonian paths are independent from $u$ to $v$ (Teng, Tan, Ho \& Hsu 2006) (Fig.8). 
$\mathrm{SW}(\mathrm{m}, \mathrm{n})$ was found to exhibit the performance of at least two MIHPs between any pair of bipartite nodes [Hsu 2013; Teng, Tan, Ho \& Hsu 2006) (Fig.8). Notably, MIHP is considered for parallel, packet wireless information transmission, diagnosis and provision of additional ciphered information, which is considered important for offering real-time private information to logistic consigners. The mechanism of mutually independent Hamiltonian paths can be applied to parallel processing. Nevertheless, in this study, such a feature was considered for dynamic cypher coding or secret communications (Lee, Boyer \& Drexelius 2005) (Fig.8).
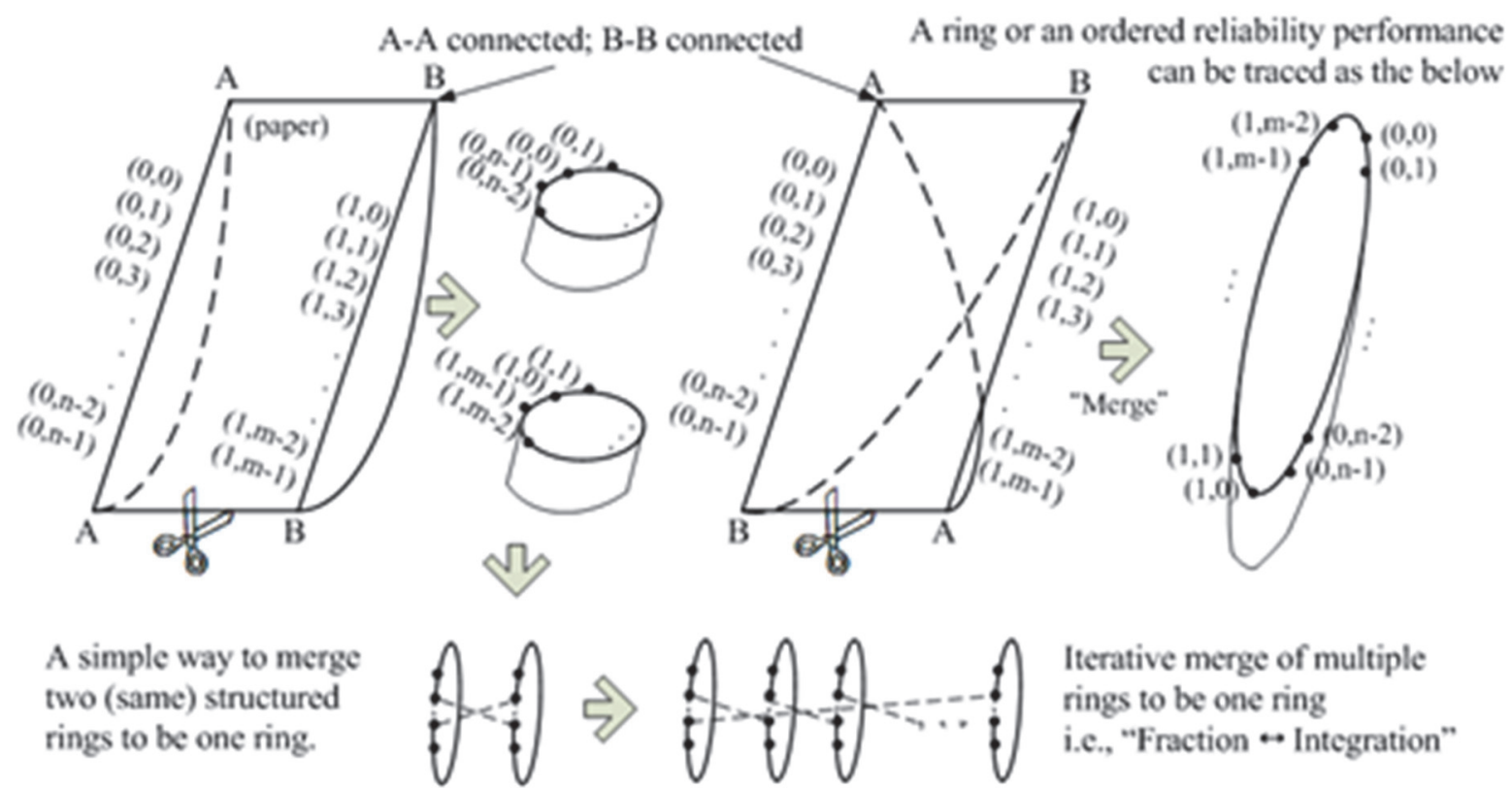

Iterative merge of multiple rings to be one ring i.e., "Fraction $\cdots$ Integration"

Figure 7. A mathematical concept for merging rings iteratively - forming a manageable, maintainable (Hamiltonian) order

Frequently maintenance inspection (flexibly) through the mutually independent Hamiltonian paths help comparatively analyze interference $(\mathcal{N})$, and flexibly offer a dynamic cipher coding mechanism.

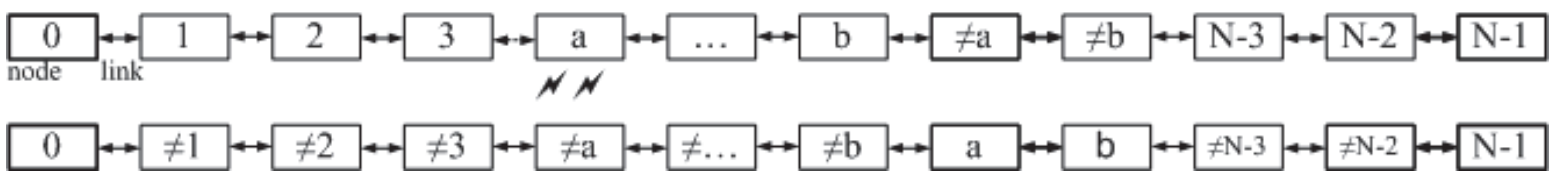

Figure 8. Diagnose interference and assign cipher codes via "mutually independent Hamiltonian path" feature

The definition of hypercubes is given as follows. Let $u=b_{n-1} \ldots b_{i} \ldots b_{0}$ be an $n$-bit binary string. For any $j, 0 \leq j$ $\leq n-1$, we use $(u)^{j}$ to denote the binary string $b_{n-1} \ldots b_{j} \ldots b_{0}$. Moreover, we use $(u)_{j}$ to denote the bit $b_{j}$ of $u$. The Hamming weight of $u$, denoted by $\mathrm{wH}(u)$, is the value of $\left|\left\{0 \leq i \leq n-1 \mid(u)_{i}=1\right\}\right|$. The $n$-cube (or hypercube) $\mathrm{Q}_{n}$ consists of $2^{n}$ nodes and $n 2^{n-1}$ links (Fig.9). Each node corresponds to an $n$-bit binary string. Two nodes, $u$ and $v$, are adjacent if and only if $v=(u)^{j}$ for a certain $j$, and we call link $\left(u,(u)^{j}\right) j$-dimensional. The Hamming distance between $u$ and $v$, denoted by $h(u, v)$, is defined as the number of elements in $\left\{0 \leq i \leq n-1 \mid(u)_{i} \neq(v)_{i}\right\}$. Hence, two nodes, $u$ and $v$, are adjacent if and only if $h(u, v)=1$.

The cube-connected cycle graph, $\mathrm{CCC}_{n}$ has $n 2^{n}$ nodes, labeled as $(l, \boldsymbol{x})$, where $l$ is an integer between 0 and $n-1$, and $\boldsymbol{x}$ is an n-bit binary string. Two vertices $(l, \boldsymbol{x})$ and $\left(l^{\prime}, \boldsymbol{y}\right)$ are adjacent if and only if $\boldsymbol{x}=\boldsymbol{y}$ and $\left|l-l^{\prime}\right|=1$ or $l=l^{\prime}$ and $\boldsymbol{y}=(\boldsymbol{x})^{l}$. In the $l=l^{\prime}$ 'case, $\boldsymbol{x}$ and $\boldsymbol{y}$ only differ in position $l$. The edges that connect $(l, \boldsymbol{x})$ to its neighbors $(l+l$, $\boldsymbol{x})$ and $(l-1, \boldsymbol{x})$ are called cycle edges. Moreover, these cycle edges form a cycle of length $n$ called a fundamental cycle defined by $\boldsymbol{x}$ (Fig.9), which can represent a node (or a probe) composed of ring-networked processors. $L(n)$ is the set offering all possible lengths of cycles in $\mathrm{CCC}_{n}$ (Hsu 2013); for $n=2, \mathrm{CCC}_{n}$ is only the cycle of length 8. 
The possible length parameter can be applied for systematic checking and design regarding affiliated processors.

"Visible" health issues typically generate greater awareness and concern, compared with "invisible" security issues (as Table 1), the risks for which are therefore rarely assessed. Nevertheless, regarding customer (or people) based service, safety and security should be thoroughly considered by planning professionals (Sussman 2005). Consequently, the previously mentioned preliminaries were referred for prototyping a security information network with dual or multiple nodes to identify targets in dynamic environments. In living creatures, surveillance of sounds, smells, images and (even) touch-related feelings is naturally "pair" or "multinode" (analogously as the compound eye of insects) based; therefore, the network prototype proposed here employs this mechanism.

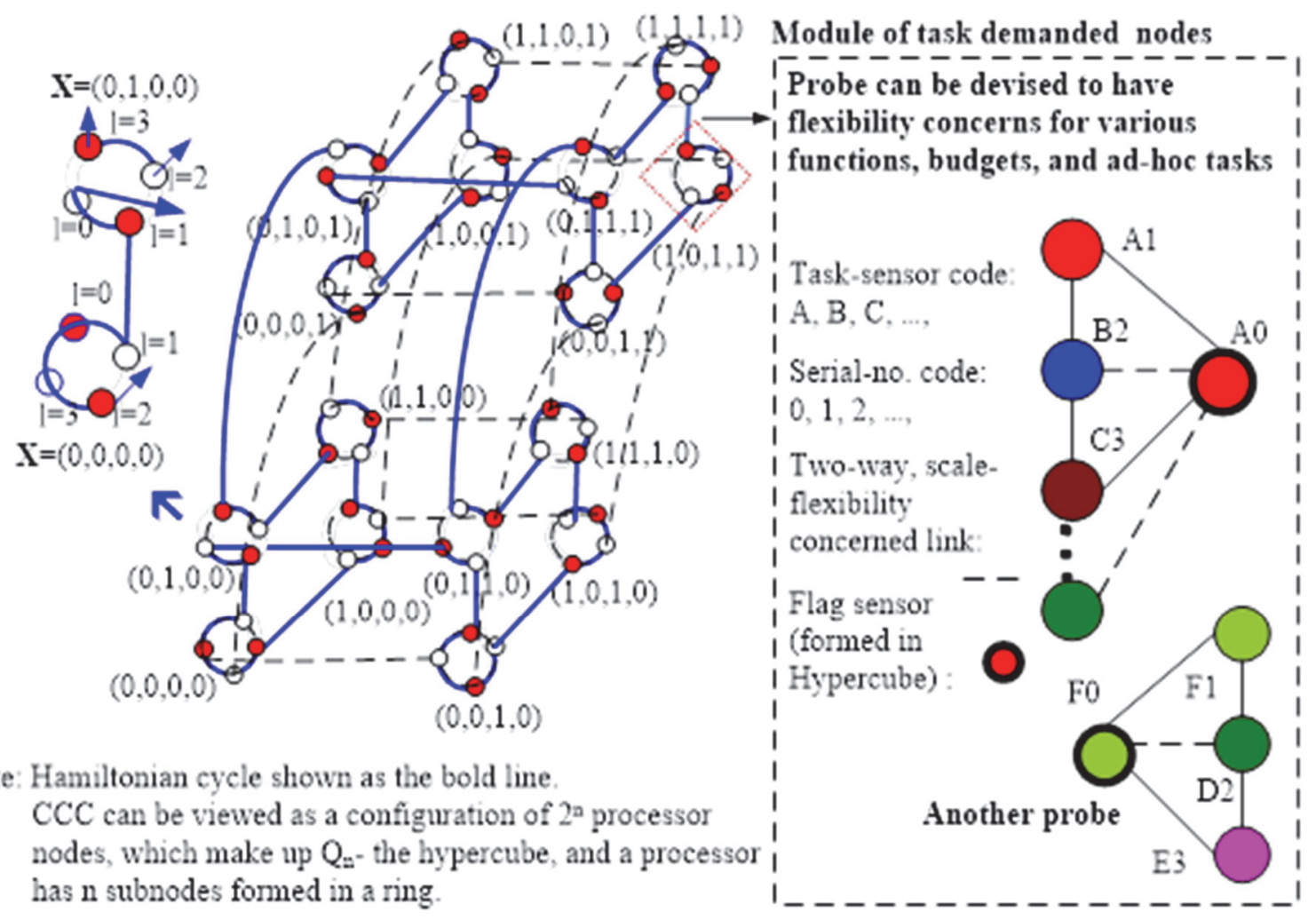

Figure 9. Probe concept and the relationship between hypercubes and cube-connected cycle, CCC4 (Hsu 2013)

Table 1. Welfare trust correlated with empathetic facility development (a Kinmen resident inquiry surveyed by the author, 2012)

\begin{tabular}{|c||c|c|c|c|}
\hline \multirow{2}{*}{ Welfare } & \multicolumn{2}{|c|}{ Security } & \multicolumn{2}{c|}{ Health } \\
\cline { 2 - 5 } & $\begin{array}{c}\text { Terrorist } \\
\text { attacks }\end{array}$ & $\begin{array}{c}\text { Smuggling, } \\
\text { Social Crimes }\end{array}$ & \multicolumn{2}{|c|}{} \\
\hline $\begin{array}{c}\text { Importance Rank } \\
(1 \text { to 5), 36 samples }\end{array}$ & $\frac{\mathbf{4 . 6 7}}{(<)}$ & $\underline{\mathbf{4 . 7 5}} \quad(<)$ & \multicolumn{2}{|c|}{$\underline{\mathbf{4 . 8 1}}$} \\
\hline Empathetic Facilities & Detection & Detection & Universal Environment & Detection \\
\hline Significance Level & 0.01 & 0.01 & 0.01 & 0.05 \\
\hline Pearson Correlation & 0.77 & 0.75 & 0.69 & 0.33 \\
\hline
\end{tabular}

\section{Features}

Regarding the suitability of research methodology, e.g. "2016 Taoyuan bus fire" on Fig.1, justifies that the prototyped plural-surveillance approach in DSRC of the ITS is needed. Similar to people's using two (dual) eyes, two ears and other sensory; a real-time reliable surveillance needs such creature mechanism, i.e., availability, to 
count blind spots, to distinguish a little difference, to confirm messages, and/or to concern node fault-tolerance, and node reliability.

Effective maintainability of a relative large amount of nodes, especially on those security related ones, should concern the sequential inspection without loss and repetition; such operation is the proved mathematical Hamiltonian. The Hamiltonian cycle also can support some edge fault-tolerance (reliability); more fault-tolerance can be supported through 1-edge Hamiltonian and/or 1p-Hamiltonian, which can casually help the network element's repairing (different from the need of the probe application). Proved laceability of the bipartite spiderweb network helps establish network hierarchies and the aerial connectivity, or spatial flexibility in promoting smart urban growth. The bipartite spider-web network naturally is dual-node prototype based. However, it also can be adapted, specifically, for example, to merge sub-nodes. The cube-connected cycle is considered for the probe application; it can support availability on both terms-Hamiltonian cycles and plural surveillance. Prototyped mathematical models can also support scalability, which helps accommodate different conditions, such as the path width and the traffic volume.

One road-segment can be considered as one link and integrally combined into a spider-web-like network, following the theoretical concept of radial-rings extending from the center. Such radial-ring networks possess link fault tolerance. Consequently, regarding local governance, the entire area holistically covered by the network can be reliably informed and controlled. Those areal networks composed of roads or paths as links are generally reliable (both node and link fault tolerant), available (featuring real-time occlusion prevention and detection of vehicles) and maintainable (possessing effective and efficient sequential order for processing security-based inspection).

National developments should not compromise needs of future generations in creating goods (Orsato 2016). Consequently, providing sensitive plural surveillance as the method for problem solving, reliable informationservice infrastructures for place security, supporting mobile information and logistic development is needed. They naturally need holistic observations in trustworthy ways (i.e., availability, reliability, maintainability) to counter environmental changing, disasters, and any other unexpected events. Intentional crimes or terrorist activities should be counted particularly, though mostly from the sightline perspectives as, since the last century, the situation is changing, e.g., the criminal medium or the cruel behavior occurred at the "2016 Taoyuan bus fire" can hardly be discovered by only the vision sensory.

From the lesson of this fire, in dangerous, conflict sensitive areas, developing a ubiquitous safety infrastructure is needed. Further surveillance control technologies, including those for promoting radio information integrity, are needed along paths, especially for managing radio-advanced, unmanned aerial vehicles (drones). MIHP performance can benefit the privacy protection from the coding through the active radio frequency identification (Fig.8).

In general, mathematical networks are prototyped with fault tolerance, Hamiltonian order (operating maintenance without loss and repetition), connectivity, scalability, countering electromagnetic interference, protecting privacy through cipher coding, and reliable accuracy through plural (dual) detection. Moreover, as shown in Fig.4, the grid path pattern can be adapted to the radial-ring pattern, with which the spider-web network prototype can consequently form a resilient areal (path) network of (sensor-information) networks, which offers availability (holism), flexibility (future land-use coordination), and adaptability (facility coordination).

In other words, the task of this research includes concerning the areal resilience, such as countering a segment of a road being highly crashed by the earthquake or terrorist bombs. More than one paths' resilience is probably adaptable from the proposed prototype but not discussed here. Besides, how more effectiveness increased from the collaboration of the MIMO is also beyond this research.

Further application of other network types, including those related to more flexibility, can potentially be justified for the emerging pervasive logistic and security demand. The spider-web network can increase operational flexibility, as in Fig.6(b), analogously. Moreover, Tulous' well-formed Gestalt radial-ring pattern (Malnar \& Vodvarka 2004) can be both historically and mathematically justified in supporting robust information services, humanistic care, and peace images. Therefore, such radial-ring images can be firstly suggested in Kinmen for cultural place marketing, to strategically benefit sustainable cross-border placemaking.

\section{Discussion and Suggestion}

\subsection{Creating an Island Park and Museum with Adaptation, Connectivity and Legibility}

Through interconnections among outer and inner radial-rings, the Testudo formation used by the Romans afforded a competitive advantage on the battlefield (Fig.3). The Fujian Tulous, featuring defensive radial-rings, have been deemed world heritage sites, replete with cultural, economic, and historical values. Scattered military locations 
were connected to prepare for potential attacks from 1949 until the 1990s; thus, Kinmen possesses a strong yet indistinct radial-ring formation. Consequently, peace-building in Taiwan and the greater Asia-Pacific region are markedly affected by the status of Kinmen

Massive Tulou-like buildings in Kinmen are overly conspicuous and therefore unfit for use in countering intentional attacks, most likely from the sea, within a very limited time. Natural waterways forming radial-rings are observable in the map of Kinmen, similar to the canals of Amsterdam. Formation models should be adapted if environmental conditions are different (e.g., the outer rings of the "canals of Amsterdam" are closely separated rings near the shoreline), and the mathematical spider-web can therefore be maintained.

Related benefits derived from such radial-ring formations related to historical events generally pique the interest of tourists. Moreover, a topological radial-ring formation with secondary deformation possibilities [Salingaros 2005; Cohen 2001], such as that of Kinmen, features an inherent radial orientation (Fig.10) and can be used as a platform for creating spatial-time rhythmic art. An island park and museum can be established to encompass the present national park, showcasing the 1,000-year history, battlefield heritage, and potential of the island.

The connectivity in the proposed networks (Fig.6, Fig.9), used for transmitting security information, can enable management of vehicle facilities [Hsu 2013] and narrow paths in decay or expected urban renewal areas. Land use can be integrated (through connectivity) to ensure positive economic value. The cultural context, including inherent peace, is integrally considered in this suggestive planning to increase the mutual sustainability of this area (Malnar\& Vodvarka 2004; Freestone \& Gibson 2006).

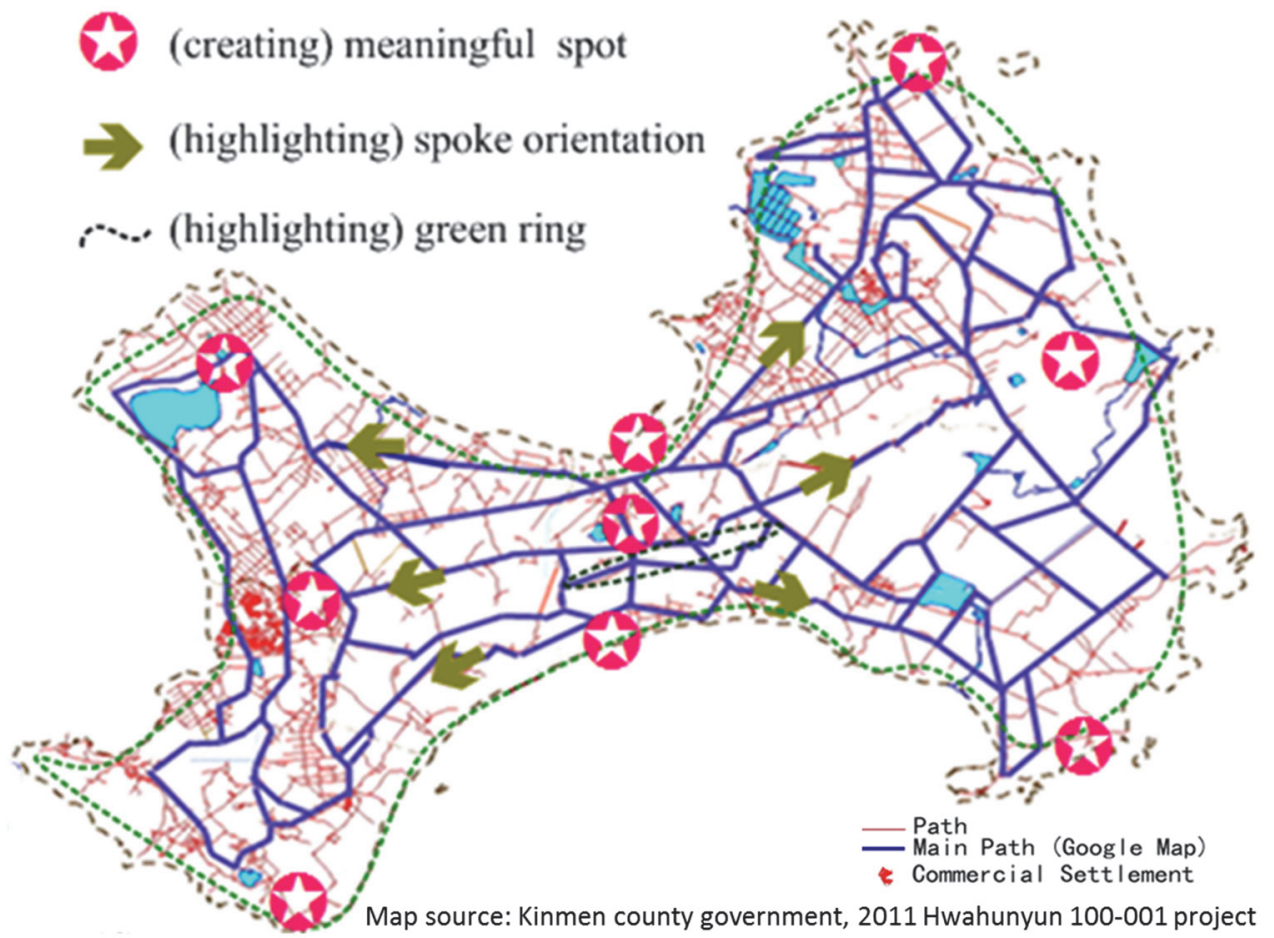

Figure 10. Strengthening Kinmen's peaceful radial-ring image [copyright inquiry available through Kinmen county government, e.g., http://leaderbox.kinment.gov.tw]

\subsection{Creating Sustainable Multimodal Transport-Related Opportunities}

Shipping by sea can generally be the cheapest means of international freight. On this basis, an aerotropolis development can help promote sea shipping, including rapid overnight freight services or cheap supply chainrelated business. Low-cost and sufficient resources enhance opportunities for developing value chained industries, including tourism. In Section 3, the potentially floatable multi-sensor packaged probe, based on the cubeconnected cycle graph, is proposed (Hsu 2013) for transmitting environmental and security-related information. Such probes can be installed along waterways and in rural areas and can enable sea rescue, navigation, drone detection and other emergency assistance, particularly during foggy seasons (related to humidity or clogged-water problems) (Hsu 2017). 
On land, methods for transmitting security information along passages involve dual (multiple) adaptable nodes, forming array-like networks which are designed to manage occlusion, interference and privacy protection in mobile environments susceptible to congestion. Such connective networks enable sequential transmission of information along the entire path in a single vehicle storage facility (i.e., parking garage or logistic processing station), integrally fusing the passages in a given area (Fig.6(a), 11(a)). This reliable method is beneficial to managing vehicle storage buildings featuring a large interior space that extends vertically without division.

Information technology should be adaptively incorporated in these types of buildings to address concerns regarding efficient operation, energy saving, environmental control (e.g., air pollution and humidity), fire protection and the well-being of residents, particularly foreign, elderly, and disabled residents. Preparing such buildings can facilitate suburban development, maintain long-term urban order and flexibly provide ideal spaces for logistic functions (Fig.11), such as service provisions in the city or future aerotropolis. Space provisions can be flexibly effective, efficient, and ecologically friendly according to changing demand of different social shifts; specifically, providing spaces for the homeless or worker dormitories, and logistical uses (Honesty 2015).

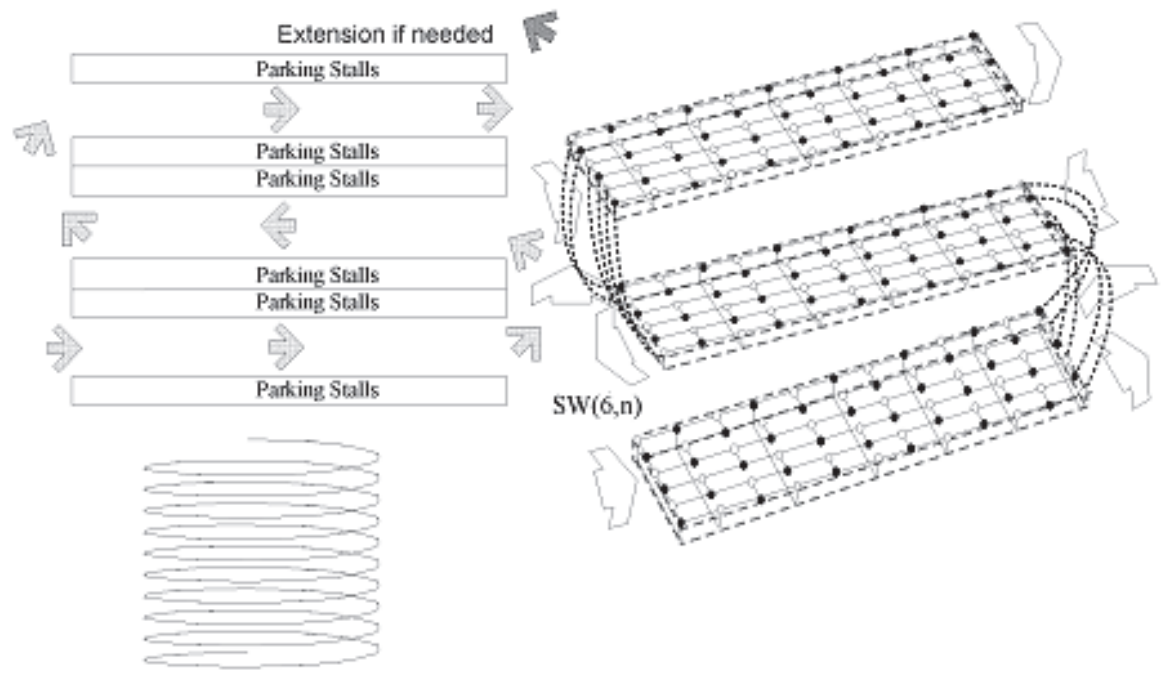

A helix circulation is used for both users
and managers in floor-to-floor dimension

(a)

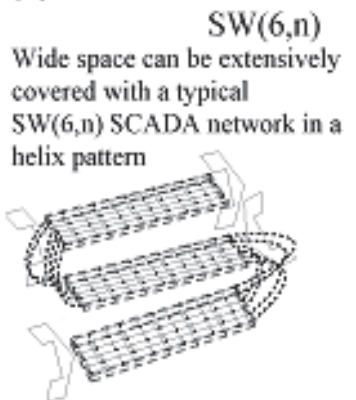

Width Adaptation

(b)

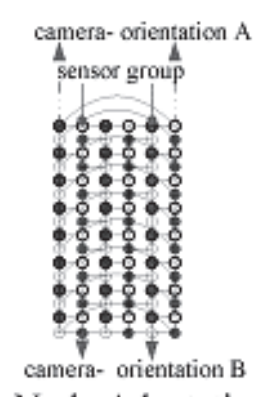

Node Adaptation

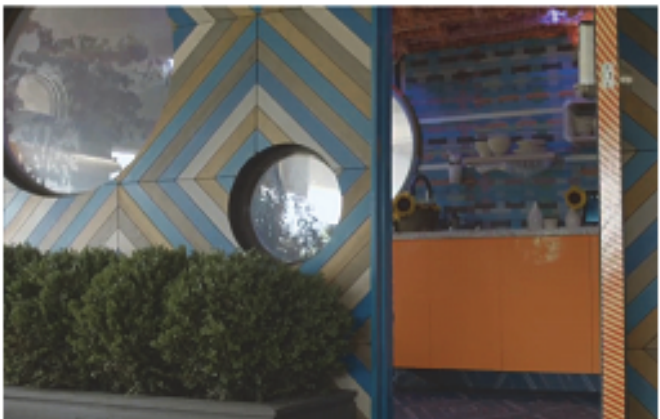

(c)

Figure 11. Vehicle circulation path integrated with an information network: (a) SW $(6, n)$ integrally adapted with the circulation path; (b) SW(6,n) adaptation examples (Hsu 2008); (c) promoting micro vertical communities within parking/logistics structures, a project at the Savannah College of Art and Design, Atlanta, GA (Honeaty 2015, photo taken from the video by the author)

Because of global ecologic needs and technological capabilities, an increasing number of mega-buildings with efficient and risk-sensitive features can be designed. Such buildings generally require automatic environmental control systems, which should be integrated but dividable (hierarchical) networks featuring radio interference- 
related availability, reliability, and maintainability characteristics.

\subsection{Developing the Strategic Planning for Cross-Border Regulation and Cooperation}

Kinmen and Xiamen have served as the battlefront of Chinese campaigns for over 50 years. However, through recent efforts, they are gradually becoming a city pair. Furthermore, capital investment in Xiamen will involve constructing a large airport at the original territory of Kinmen and can potentially enhance the well-being of Kinmen residents. For efficient placemaking, however, trust networks are generally implemented on a social basis, i.e. collectively being formed from residents' reliability experiences and recognition (Tilly 2011).

In the past century, cross-border place-makings, such as those in the Niagara Falls area (Shibley, Schneekloth \& Hovey 2003) and the Wadden Sea, a newly announced world heritage adjacent to Denmark, Germany and the Netherlands, have been considered peaceful and meaningful regarding the environmental protection and economic development. Their dangers and vulnerabilities should be assessed concurrently. In conflict sensitive regions, robust, trustable social order is essential. The status of regional peace can be revealed through the global media.

To benefit travelers, tourists and residents in Kinmen, a network for transmitting mobile business and safety information with sufficient reliability, availability and maintainability (Daley 2011; Knezevic 1997) regarding spatial information in undesirable conditions is discussed. Furthermore, citizen investment and participation intentions can be substantially affected by the encountered risk level (Peyroux \& Pütz 2012). Trust is built from the mind; contemporary governance should be considerate, loyal (Robbins \& Coulter 2012) to customers and compatriots. Cross-border placemaking in Kinmen-Xiamen can be empathetically globally marketed using a reliable platform to avoid unnecessary military actions, or distrust on both sides.

The condition of unavailability, e.g. falsely charging those who did not use the tolled facilities, can cause distrust (Lee 2014). On the contrary, the detection availability, e.g. cameras (probably with closed-circuit television) being installed in public spaces or vehicles (including buses), has largely been accepted nowadays because such devices can fairly provide a platform for transparently protecting customers, operators (drivers), and administrators (firms). Moreover, in the real-time, the evidence availability can assist in profiling an event (Bloom 2013). The well-being of Kinmen residents can potentially be optimized. Moreover, the trust thereby facilitated can gain global attention, and this method of economic enhancement and maintaining peace is hoped to become a global reference for crossborder cooperation and the promotion of peace in conflict sensitive areas.

\section{Conclusion}

Environmental control with holistic pervasiveness is getting more importance in the current age of climate change, terrorism, and information. Well enhancing dependable capabilities to optimally utilize neighboring resources and/or counter complex, wicked issues can be a practical public policy. For many other borderlands where adversary conditions can easily be aroused, that developing a reliable, "proactive" platform to promote well interactions between two conflict-sensitive entities through mutual trust enhancing and economy developing can be an essential vision reference.

On countering such urban wicked problems, prototyping, which is supported with evidences and/or proved features, is a solid methodology. Consequently, a sensor-information infrastructure is prototyped with dependable capabilities, including availability, reliability, and maintainability, to manage the uncertainty. The mathematical spider-web network and the cube-connected cycle graph are prototyped with fault tolerance, Hamiltonian order, connectivity, scalability, electromagnetic interference countering, privacy protecting through cipher coding, and reliable accuracy through plural (dual) detection.

The spider-web network can be a basic areal sensor-information network; moreover, by further applying other network types, e.g. on managing the legal use of drones; more flexibility or strength can naturally be justified. The cube-connected cycle is considered for the scattered probe application. This can be installed along waterways and in rural areas and can enable sea rescue, navigation, drone detection and other emergency assistance, particularly during foggy seasons.

Nevertheless, the prototyped spider-web network can well form a flexible and resilient "network of networks" due to its taking advantage of topologic radial-ring, which is the main pattern of "city-building." Its areal fault-tolerance can counter a segment of a road being highly crashed. Besides, the well imaged defensive heritages, Tulous can be mutually applied in peace and economy oriented cultural marketing, due to its radial-ring wholeness cognition as well as the similarity and differences in that of neighboring Kinmen.

\section{Acknowledgments}

The author is deeply grateful for the supports from Kinmen county government and for the discussions with 
colleagues, including those in his briefing at the tri-yearly global conference of the World International Studies Committee, 2017 WISC.

\section{References}

(APSC) Australian Public Service Commission (2007). Tackling wicked problems: A public policy perspective (pp. 1-2). Commonwealth of Australia.

Anderson, J., Kalra, N., Stanley, K., Sorensen, P., Samaras, C., \& Oluwatola, O. (2016). Autonomous vehicle technology - A guide for policymakers (pp.71-80). Santa Monica, CA: RAND Corporation. Retrieved from http://www.rand.org/pubs/_reports/ RR443-2.html

Arthur, P., \& Passini, R. (1992). Wayfinding - People, signs, and architecture (pp. 84-115, p. 224). New York, NY: McGraw-Hill.

Ashford, N., Mumayiz, S., \& Wright, P. (2011). Airport engineering: Planning, design, and development of 21 st century airports (pp. 660-665, pp. 679-684). Hoboken, NJ: Wiley.

Atlas, R. (2013). 21st century security and CPTED: Designing for critical infrastructure protection and prevention (pp. 19-21, p. 422). Boca Raton, FL: CRC Press.

Batty, M. (2008). The size, scale, and shape of cities. Science, 319(5864), 769-771.

Batty, M., \& Longley, P. (1994). Fractal cities: A geometry of form and function (pp. 7-8). London, UK: Academic Press.

Bickel, J., Kusel, T., \& King, E. (1996). (Eds) Tunnel engineering handbook (p. 495). New York, NY: Chapman.

Bloom, R. (2013). Foundations of psychological profiling: Terrorism, espionage, and deception (p. 28, p. 46, pp. 86-89). Boca Raton, FL: CRC Press.

Brenner, N., \& Keil, R. (2006). The global cities reader (p. 4). New York, NY: Routledge.

Caudle, S. (2009). National security strategies: Security from what, for whom, and by what means. JHSEM, 6(1), Article 22.

CNA. (2014, July 28). Kinmen seeking to co-build, co-operate airport in Xiamen. The China Post. Retrieved from http://www.chinapost.com.tw/taiwan/local/offshore-islands/2014/07/28/413418/Kinmen-seeking.htm.

Coaffee, J. (2003). Terrorism, risk and the city: The making of a contemporary urban landscape (p. 8, pp. 218227). Brookfield, VT: Ashgate.

Coaffee, J. (2009). Terrorism, risk and the global city: the resilience (p. 292). Farham, Surrey: Ashgate.

Cohen, P. (2001). Contested symmetries - And other predicaments in architecture (pp. 94-95). New York, NY: Princeton Press.

Daley, D. (2011). Design for reliability: Developing assets that meet the needs of owners (p. 19, p. 203). New York, NY: Industrial Press.

De Neufville, R., \& Odoni, A. (2003). Airport systems: Planning, design and management (pp. 59-75). New York, NY: McGraw-Hill

De Neufville, R., \& Scholtes, S. (2011). Flexibility in engineering design (pp. 15-30). Cambridge, MA: MIT press.

Dovey, K. (2016). Urban design thinking: A conceptual toolkit (pp. 81-82), London, UK: Bloomsbury.

Fischbacher-Smith, D. (2016). Framing the UK's counter-terrorism policy within the context of a wicked problem. Pubic Money and Management, 36(6), 399-408.

Fisher, T. (2013). Designing to avoid disaster: The nature of fracture-critical design (pp. 5-7, p. 194, p. 250). New York, NY: Routledge.

Fisher, T. (2014). Public values and the integrative mind: how multiple scores can collaborate the city building. PAR, 76(4), 457-464.

Freestone, R., \& Gibson, C. (2006). The cultural dimension of urban planning strategies: An historical perspective. In J. Monclus, \& M. Guardia (Eds.) Culture, urbanism and planning (pp. 21-41). Burlington, VT: Ashgate.

Gómez-Ibáñez, J., \& Small, K. (1994). Road pricing for congestion management: A survey of international practice (p. 10, p. 26). Washington, DC: Transportation Research Board, National Research Council, National Academy press.

Goodwin, J. (2011). Spotlight: Terrorism. In M. Hanagan, \& C. Tilly (Eds.), Contention and trust in cities and 
states (p. 169). New York, NY: Springer.

Gottdiener, M., \& Budd, L. (2005). Key concepts in urban studies (p. 113, p. 136, p. 186). London, UK: Sage.

Graham, S. (2004). Introduction: Cities, warfare, and states of emergency. In S. Graham (Ed.), Cities, war, and terrorism: Towards an urban geopolitics (pp. 1-25). Madden, MA: Blackwell.

Grant, R. (2014). Contemporary strategy analysis (p. 112). Chichester, UK: Wiley.

Hill, C., Schilling, M., \& Jones, G. (2017). Strategic management: Theory \& cases: An integrated approach (p .46, p. 84). New York, NY: Cengage.

Honesty, L. (2015, June 2). Checking in with SCAD's parking garage micro community. Architect Magazine Newsletter. Retrieved from_http:/www.architectmagazine.com/videos/checking-in-with-scads-parkinggarage-micro- community

Hoppe, L., \& Awsede, L. (2013). Design of control of UAV objects. In A. Nawrat, K. Simek, \& A. Swieriak (Eds.), Advanced technologies for intelligent systems of national border security (pp. 211-220). New York, NY: Springer.

Hsu, L. H., \& Lin, C. K. (2008). Graph theory and interconnection networks (pp. 1-20). Boca Raton, FL: CRC.

Hsu, L.-Y. (2008). Networking dual-surveillance/dual-pair-tele-paths for critical urban areas. J. Southeast Univ. Eng. Ed, 24(S), 114-119. Retrieved from http://www.cnki.com.cn/Article/CJFDTotalDNDY2008S1023.htm

Hsu, L.-Y. (2013). Ubiquitous integrity via network integration and parallelism - sustaining pedestrian / bike urbanism. Algorithms, 6(3), 459-470. https://doi.org/ 10.3390/a6030459

Hsu, L.-Y. (2017). Building Taiwan aeropolis of airports through infrastructuring care and integrity. JCEA, 11(6), 608-615. https://doi.org/ 10.17265/1934-7359/2017.06.007

Kao, S.-S., \& Hsu, L.-H. (2005a). Spider-web networks: a family of optimal, fault tolerant, Hamiltonian bipartite graphs. JAMC, 160, 269-282.

Kao, S.-S., \& Hsu, L.-H. (2005b). Hamiltonian laceability of spider-web networks. Chung Yuan J. (Taiwan), 33, $1-10$.

Keeble, L. (1969). Principles and practice of town and country planning (p. 102, p. 112). London, UK: Estates Gazette.

Knezevic, J. (1997). Systems maintainability - Analysis, engineering and management (p. 11, p. 221). London, UK: Chapman Hall.

Lee, A., Boyer, J., Drexelius, C., Naldurg, P., Hill, R., \& Campbell, R. (2005). Supporting dynamically changing authorizations. In D, Hutter, \& M. Ullmann (Eds.), Pervasive communication systems in security in pervasive computing, LNCS3450 (pp. 134-150). New York, NY: Springer.

Lee, J. (2014, Jan. 16). Freeway bureau set to probe FETC methods. The China Post. Retrieved from https://chinapost.nownews.com/20140116-79396

Levy, S. (2007). Project management in construction (pp. 355-374). New York, NY: McGraw-Hill.

Li, F. (2013). Interference cancellation using space-time processing and precoding design (p. 2). New York, NY: Springer.

Lynch, K. (1960). The image of the city (p.2). Cambridge, MA: MIT Press.

Malnar, J., \& Vodvarka, F. (2004). Sensory design (p. 6, pp. 44-46). Minneapolis, MN: Univ. of Minnesota Press.

Orsato, R. (2016). Sustainability strategies: When does it pay to be green (p.4)? New York, NY: Palgrave.

Perulli, P. (2017). The urban contract: Community, governance and capitalism (p. 110, pp. 168-180). New York, NY: Routledge.

Petvich, C. (1993). Science and the inherently subjective: The evolution of aesthetic assessment since NEPA. In S. Hildebrand, \& J. Cannon (Eds.), Environmental Analysis - The NEPA Experience (pp. 249-273), Boca Raton, FL: CRC press.

Peyroux, E., \& Pütz, R. (2012). Business improvement districts (BIDs): The internationalization and contextualization of a travelling concept. Eur. Urban Reg. Stud., 19(2), 111-120.

Robbins, S., \& Coulter, M. (2012). Management (p. 473), $11^{\text {th }}$ ed. Upper Saddle River, NJ: Prentice Hall. 
Saha, D., Mkheryjee, A., \& Bandyopadhyay, S. (2012). Networking infrastructure for pervasive computing: Enabling technologies and systems (p. 2, p. 52). New York, NY: Springer.

Salingaros, N. (1999). Architecture, patterns, and mathematics. Nexus Network J, 1, 75-85.

Salingaros, N. (2005). Principles of urban structure (p. 17, pp. 40-41, pp. 116-117, pp. 139-170, p. 190). Amsterdam, the Netherlands: Techne Press.

Salingaros, N. (2010). Twelve lectures on architecture - Algorithmic sustainable design (p. 70). Wilmington, DE: ISI Books.

Sassen, S. (2015). Epilogue (Urbanizing Technology). In M. Foth, M. Brynskov, \& T. Ojala (Eds.), Citizen's right to the digital city: Urban interfaces, activism, and placemaking (pp. 252-256). New York, NY: Springer.

Schneekloth, L., \& Shibley, R. (1995). Placemaking: The art and practice of building communities (pp. 109-120, p. 229). Hoboken, NJ: Wiley.

Shibley, R., Schneekloth, L., \& Hovey, B. (2003). Constituting the public realm of a region: placemaking in the bi-national Niagaras. JAE, 57(1), 28-42.

Slessor, C. (2018, Feb.) The new London embassy. J. AIA, 70.

Steinfeld, E., \& Maisel, J. (2012). Universal design: Creating inclusive environments (p. 14, pp. 51-52, pp. 7172). Hoboken, NJ: Wiley.

Stevens, N., Baker, D., \& Freestone, R. (2010). Airports in their urban settings: towards a conceptual model of interfaces in the Australian context. J. Transport Geography, 18, 276-284.

Stojmenovic, I. (1997). Honeycomb networks: Topological properties and communication algorithms. IEEE TPDS, 18(10), 1036-1042.

Sussman, J. (2005). Perspectives on intelligent transportation systems (pp. 24-25, pp. 47-50). New York, NY: Springer.

Syrett, M., \& Devine, M. (2012). Managing uncertainty: Strategies for surviving and thriving in turbulent times (p. 13). London, UK: Profile Books.

Terlouw, K. (2012). Border surfers and euro regions: Unplanned cross-border behaviour and planned territorial structures of cross-border governance. PPR, 27(3), 351-366.

Tilly, C. (2011). Cities, states, and trust networks: Chapter 1 of cities and states in world history. In M. Hanagan, \& C. Tilly (Eds.), Contention and trust in cities and states (pp. 3-7). New York, NY: Springer.

Tumlin, J. (2012). Sustainable transportation planning tools for creating vibrant, healthy, and resilient communities (pp. 2-5). Hoboken, NJ: Wiley.

Weber, R. (2002). Extracting value from the city: Neoliberalism and urban redevelopment. In N. Brenner, \& N. Theodore (Eds.) Spaces of neoliberalism - Urban restructuring in north America and western Europe (p. 176). Madden, MA: Blackwell.

WOX. (2014, July 29). Kinmen seeks to co-share Xiamen's new airport in Xiang'an district. Whats on Xiamen. http://www.whatsonxiamen.com/ news36557.html

Ye, M. (2014). Diasporas and foreign direct investment in China and India (p. 159). New York, NY: Cambridge University Press.

Yigitcanlar, T. (2014). Position paper: Benchmarking the performance of global and emerging knowledge cities. ESWA, 41, 5549-5559.

Zhou, W., Chen, F., \& Guo, H. (2015). Differential radar interferometry for structural and ground deformation monitoring: A new tool for the conservation and sustainability of cultural heritage sites. Sustainability, 7(2), 1712-1729.

\section{Copyrights}

Copyright for this article is retained by the author(s), with first publication rights granted to the journal.

This is an open-access article distributed under the terms and conditions of the Creative Commons Attribution license (http://creativecommons.org/licenses/by/4.0/). 